\title{
Folgen unzureichender Entfernung und wirksame Kontrolle des dentalen Biofilms
}

Schöne, gesunde Zähne gelten in unserer Gesellschaft als erstrebenswertes Ideal. Basis für den langfristigen Erhalt der Zahngesundheit ist ein gutes Biofilmanagement. Die mangelnde Kontrolle des

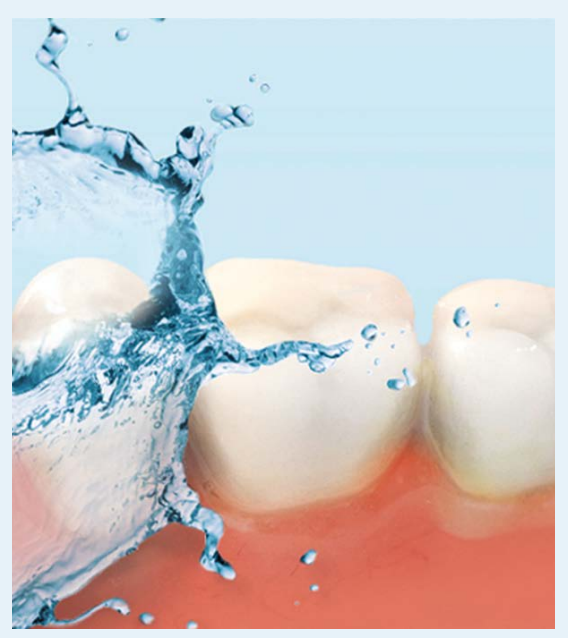

dentalen Biofilms kann ernstzunehmende Erkrankungen des Mundraums, wie Karies, Gingivitis oder Parodontitis, zur Folge haben. Im Rahmen der täglichen 3-fach-Prophylaxe wird die mechanische Zahnreinigung, mittels Zahnbürste und Interdentalreinigung, durch die Anwendung einer antibakteriellen Mundspülung optimal ergänzt. Mundspülungen mit ätherischen Ölen, wie Listerine, zerstören die bakteriellen Zellwände, sodass der nach der mechanischen Zahnreinigung verbliebene Biofilm gelockert und gelöst wird. So kann eine neue Bakterienakkumulation zeitlich verzögert werden. $\mathrm{Zu}$ dem wirken Mundspülungen auch an Stellen, die mit Zahnbürste und Interdentalpflege schlecht zu erreichen sind.

Nach einer Pressemitteilung der Johnson \& Johnson GmbH, Neuss www.listerine.de 